\title{
Proceedings of the Sixty-Fifth Annual Meeting of The American Society for Clinical Investigation, Inc. Atlantic City, New Jersey, 30 April 1973
}

\author{
PRESIDENTIAL ADDRESS
}

\section{The Time for Reflection: a Luxury of the Past}

\author{
NeAL S. Bricker \\ From the Department of Medicine, Albert Einstein College of Medicine, Bronx, New York 10461
}

Within the last three decades, there has occurred a spectacular explosion of knowledge about the diseases that afflict mankind. The new information ranges over the entire biologic basis of disease and includes new methods of detection, prevention, palliation, and cure. Hundreds of previously unknown diseases, including over 130 genetic abnormalities, have been recognized and described. Successful vaccines have been developed for polio, measles, and rubella. We have the capability for preventing acute rheumatic fever, for eradicating syphilis, and for preventing gonorrhea in the newborn. Many of the great scourges of mankind, including smallpox, rabies, plague, cholera, and most recently tuberculosis, have either been eliminated from this country, or their incidence strikingly reduced. Two techniques, organ transplantation and hemodialysis, can prolong the lives of patients with end-stage kidney disease. Cures have been effected in early Hodgkin's disease, and complete remissions-some for years-are no longer a rarity in acute leukemia. Surgical techniques have been developed for correcting many forms of congenital heart disease and valvular disease and an increasing number of lives are being saved through the implantation of cardiac pacemakers. It is an overall testimony to these advances that life expectancy in 1973 in the United States is almost 20 years longer than it was at the turn of the century.

But the advances in knowledge, though striking-and I have listed only a small fraction of them-stand as insignificant in relation to the job yet to be done. In some areas we appear to be on the threshold of truly momentous accomplishment. For example, there is growing evidence to implicate viruses in the etiology of human cancers, degenerative diseases of the nervous system, and possibly systemic lupus erythematosus; and there is equally impressive evidence to implicate abnormalities of the immune system in the pathogenesis of cancers, as well as diseases of the kidneys, the thyroid, the liver, the joints, and indeed, virtually every organ in the body.

But in other areas, including major forms of heart disease, arteriosclerosis, and the conglomerate abnormalities termed "aging," our knowledge remains limited, and the breakthroughs seem farther off.

The potential for future progress, as well as the conquests that have already been made, not only in laboratories in the United States but throughout the world, stem in large measure from a system that has been created and nurtured wholly within the United States. The system has been funded by the Federal government, and has had as its focal point the National Institutes of Health. It has had as its central thesis the parallel support of research training and of biomedical science. The major criterion for support has been excellence. The recruitment of new scientists into the program and the support of established scientists, have been based primarily on the merit of the individuals and the merit of their ideas. An internal self-policing system consisting of not one, but two, levels of "peer review" has selected out for quality and innovativeness.

The system has not been perfect, but it obviously has 
worked and worked well. To dismantle this system, or to change its character in a fundamental way, without indepth, detailed, and soul-searching analysis of the potential consequences, and without the prior development of a better system to supplant it, is to take a great and unacceptable risk with the future lives and destinies of present and unborn generations.

This system is now in trouble. It is under more serious attack than at any point in its history. And, I am not convinced that the reasons for the attack have arisen out of the type of in-depth analysis that is required. Nor do I believe that there is an alternative model that can maintain the present momentum in the drive to conquer the major unsolved diseases.

The present threat has three major elements: (1) the termination of Federal support for training of new biomedical scientists and teachers, (2) the downgrading of basic research, and (3) the reallocation of funds from research grants to government contracts.

\section{TRAINING}

I cannot believe that anyone wishes to stop the flow of the brightest and most talented young people into the fields of biomedical research and teaching. There simply is too much at stake. There does, however, appear to be a difference of opinion as to how much the recruitment and training of these gifted individuals is worth to this nation. The total cost in 1972 of all of the Federally supported research training grants, fellowships, career development awards, research career awards, and M.D.-Ph.D. programs was $\$ 186,000,000$. This is equal to $16 / 1,000$ of $1 \%$ of the Gross National Product, or $2 / 10$ of $1 \%$ of the total national expenditures for health. Put into another frame of reference, the cost of training a single productive investigator is less than $2 \%$ of the moneys he will expend during his career.

The executive branch of government has begun a policy of phased termination of all Federally supported research training programs. Thus, the mechanism of funding that has been developed over a 20 -year period is now being dismantled.

It is the position of the Administration that: (1) An excess of qualified manpower exists in many areas of biomedical research; and the normal forces of supply and demand will provide any needed replacements. (2) The Federal government does not support graduate training in many other professions. Thus, eliminating research training support will erase an inequity. (3) People entering biomedical research are generally able to subsidize their own training through loans as an investment in their futures.

These arguments must be weighed with great care, for what is at stake is the health and welfare of the American people 10 years from now. I believe the arguments to be fallacious and their implementation to portend potential disaster. The reasons are as follows:

First, the question of overproduction. The major argument for an oversupply of biomedical scientists is that each year more NIH grants are approved than can be funded. The very use of this argument indicates a basic lack of understanding about the NIH grant review system and how it works.

There are in general two categories of biomedical scientists, whom I will describe as the architects and the bricklayers. The architects are relatively few in number, and it is they who provide the innovative ideas that ultimately lead to major new accomplishments in the understanding and treatment of disease. The bricklayers, on the other hand, though they may be less innovative, play an essential role in biomedical research. It is this group that tests the concepts of the architects in carefully controlled studies. I have always believed that one of the great strengths of our system of biomedical research in this country, and a principal reason for its preeminent success, has been the ability to fund the bricklayers as well as the architects.

. The way the grant system works is as follows: applications to the NIH are reviewed at regular intervals by expert committees selected from our own ranks. Allowing for human error, all of the well-conceived innovative grants are approved and given high enough priorities to assure funding. Those applications that are considered sound, though not necessarily innovative or original, are also approved, but given lower priorities. How many of the latter are funded depends upon the amount of money available each year.

I believe that society would be benefited if more money were made available to increase the number of approved grants that can be funded. But I find it inconceivable that the request for such money can be construed as prima-facie evidence for an oversupply of biomedical scientists. It might be noted that numerous grant applications, funded and unfunded, request salary support to recruit new investigators because of a shortage of trained manpower.

There are objective criteria for evaluating the adequacy of the manpower pool. In 1972 there were over 1,400 vacant faculty positions in American medical schools, and at least 10 new medical schools are scheduled to come into existence in the near future. Moreover, as the existing medical schools continue to increase their enrollment and also to take on the responsibility for more and more areas of health care delivery, the teaching and service demands imposed upon their faculties proliferate in a seemingly inexorable fashion.

All of these activities must not only be carried out in parallel with biomedical research, but often by the same individuals. In essence, then, we are not oversupplied. 
Rather, I believe, we have a great and compelling need for more manpower.

Next, the contention that financial support for training in the life sciences constitutes an inequity since graduate students in physical sciences, engineering, public administration, the arts and humanities, etc., do not receive such support. I believe that this argument, too, fails to withstand critical review. First, it confuses graduate students with post-doctoral trainees. Second, in contrast to each of the other fields mentioned, the Federal government is the major investor in biomedical research in this country. To protect its investment, the government must see that the research apparatus is run by highly skilled personnel. And as has already been indicated, the cost of providing this manpower is remarkably small, whether expressed as a fraction of the Federal health budget or in relation to the enormous returns on the investment.

The third argument is that substituting low-cost loans for stipends will not impede the flow of manpower into the system. Once again, there are relevant data that one must assume have been overlooked.

Two recent surveys $(1,2)$ have shown that $36 \%$ of biomedical graduate students and $56 \%$ of medical students were in debt at the time of graduation. Over $50 \%$ of graduate and post-doctoral trainees were in debt at the completion of their training, some in excess of $\$ 15,000$; and $70-75 \%$ of the post-doctoral trainees interested in research indicated they would not have been able to continue their training if a low-interest loan had been available instead of a stipend.

There can be little doubt that a shift from training grants to loans will drastically reduce the number of candidates willing to enter the system; and there is a real risk we will return to an era when those that do enter will come largely from the ranks of the very rich.

In evaluating the past record of training programs, we must respond to the criticism that many physiciantrainees have left academic medicine to enter private practice. Many, indeed, have; and we must keep this in mind in planning future training programs. However, part of the "dropout" rate properly relates to the fact that some trainees discover that their strengths do not lie in biomedical research; and others discover that they are not prepared to sustain permanently the financial disadvantages of an academic career in relation to practice.

Finally, some research training funds have been earmarked to alleviate manpower shortages in clinical areas such as neurology and psychiatry. The graduates of these programs were never destined to enter medical research; and they should not now be charged against the record of the research training program.

One final point must be considered in examining the consequences of terminating research training support.
What will be the effects on the medical schools of this country? First, the loss of fellows and trainees will have a detrimental effect on both the research and teaching capabilities of their institutions. Second, training grants have provided not only trainee stipends but institutional support, including faculty salaries. A number of medical schools in this country will lose over $\$ 1$ million per year in faculty salaries. Added to this, the termination of the Research Career Development Awards will eliminate salary support for over 1,000 faculty members with established competence in research. These assaults on the financial integrity of the medical schools could not be occurring at a worse time, for the total projected loss of Federal money for faculty salaries for 1974 approximates $\$ 120,000,000$.

Despite the fact that only $4 \%$ of graduates of American medical schools enter academic careers, the Research Training Program has made it possible to attract the best caliber of student. By setting national standards, quality control has been maintained. By controlling the distribution of funds, the mix of personnel entering different areas of biomedical science has been regulated. The research training program thus has contributed heavily both to biomedical science and to academic institutions in this country. To dismantle this system peremptorily without objective evidence that a new system, or in this instance, a nonsystem, will work is at best irresponsible, and could very well prove to be catastrophic.

\section{THE DOWNGRADING OF BASIC RESEARCH}

Next, I would like to consider briefly the impact of downgrading basic research on the future of biomedical science. The evidence that basic research is being downgraded is widespread. One example is that the National Institute of General Medical Sciences, the division of the $\mathrm{NIH}$ that traditionally has directed much of its support to basic research, is scheduled to sustain the largest cut in budget of any NIH institute; and only through cutting existing commitments can any money be made available for new grant awards.

In a sense, basic research is analogous to research training. Just as an unremitting flow of creative people is essential to progress, so also is an unremitting flow of fundamental information. Without understanding the intricacies of life processes in health, we cannot hope to unravel the perturbations of these processes in disease. And, the universality of nature is such that the characterization of DNA synthesis and repair in bacteria can provide insight into how to treat genetic diseases in man, the study of ciliary motion in the oyster can lead to a new technique for detecting cystic fibrosis, and the study of the bursa of Fabricius in the chicken and the thymus 
in the mouse can extend the field of immunobiology to literally hundreds of diseases afflicting man.

Progress in the understanding of disease is the culmination of knowledge arising from many and diverse sources. In instances too numerous to count, the basic observations that led to major medical breakthroughs were made without knowledge or interest in the diseases to which the new information was ultimately applied.

\section{CONTRACTS VERSUS GRANTS}

Closely coupled to the question of the downgrading of basic research is the tendency to distribute more and more of the available funds through contracts and less and less through research grants. The use of the contract mechanism as a means of solving a major problem or achieving a major goal is well established in the physical sciences. An atom bomb was developed through a mission-oriented crash program. And man did walk on the moon less than 10 years after this nation was committed to that task. But again, major breakthroughs in the understanding of a given disease often come, from studies that relate to other diseases or from nondiseaseoriented basic research.

It is implicit in the contract mechanism that one knows the proper questions to ask and the correct approach to take in seeking the answers. And in many instances this can be both valid and effective. For example, the extensive testing of new drugs, the involvement of industry in developing special technology, and the implementation of new approaches to health care delivery all can be supported effectively through contracts. But even if all of the questions are asked by, or reviewed by, people with the deepest appreciation of the problems and needs of biomedical research, there still is great danger in shifting too much of the total research support to a system that directs the investigator to perform a specified task and limits his options to pursue promising leads that may not be related to the subject of the contract.

We are now embarking on a massive program designed to cure cancer. But there is no one in the scientific community, or any other community, who knows with certainty whether the ultimate solution to the problem will come from the ability to control infection by a putative cancer virus, from the ability to alter DNA of malignant cells, from a richer understanding of immunobiology, or from an idea not yet conceived by a trainee presently supported by a training grant who is working on the regenerating limb of the starfish.

To channel our approach to the solution of cancer or any other major unsolved disease, preferentially, through a system based on the letting of government contracts, seems particularly treacherous, especially since this must be done at the expense of a system that has had a dazzling record of achievement.

\section{THE ORIGIN OF OUR TROUBLES}

With so many positive accomplishements on record, and so much expectation for the future, why have we moved into such troubled times? Much of the problem, I believe, is of our own making. It was less than 30 years ago that the Federal government made a major commitment to support biomedical research. The initial investment was small but the rate of growth was steep. And though the growth was anticipated, little attention was paid to the fact that it would take place in a political arena. The necessity for accountability to any group, other than our fellow scientists, was therefore largely overlooked. Some members of the Congress began to call this to our attention over a decade ago, and as the annual appropriation approached and then exceeded a billion dollars, more and more of our medical statesmen began to issue warnings. We were warned that we must develop an interface with the public and their elected representatives to inform them of our accomplishments and of the return on their tax dollars. We were warned that the spiralling support for medical research would someday cease and our responsibilities then would include a mechanism for establishing priorities. Given a finite amount of money, how much should be spent for research training, how much for basic science, how much for clinical investigation, and how much for contracts versus grants? Finally, we were warned that the time would come when we would lose our favored position and would be required to compete for funds on an equal basis with agriculture, highways, housing, and defense. To succeed we would need to develop a deeper understanding of the workings of the political system.

Essentially we have failed to heed any of the warnings. Though shaken from time to time, we have never completely lost faith in our own immortality. Our interface with the public remains fuzzy, our interface with the Congress random and disconnected, and our interface with the executive branch of government virtually nonexistent. We have failed to develop priorities. And our attempts to deal with our product in cost-benefit analysis terms have been inadequate and incomplete. This is not to deny the recent efforts that have been made by some individuals and by some of our professional organizations. But basically we have remained crisis-oriented and, as in the case of the Research Training Program, we have mobilized our maximum efforts after the fact.

\section{WHERE DO WE GO FROM HERE?}

The key question is where do we go from here. I believe that the answer is clear. We cannot return to the past. The golden era is ended. Thus, we must move into the future with full awareness of our past mistakes, with full acceptance of the fact that we are part of a political 
system, but with fierce determination to preserve the excellence that has been created. I do not believe that either the legislative or executive branch of government is our enemy; nor that there is any desire to substitute mediocrity for excellence on a permanent basis. I see our responsibilities as follows:

(1) We must develop an interface with the public. The people must know of the steps that are being taken towards the eradication of suffering and death. And they must be made to realize that these pursuits are not only noble in cause, but that they represent a very sound investment of tax dollars.

(2) We must accept the fact that only part of what we think is important can be funded. We must therefore move quickly to set priorities even if, as Daniel Greenberg recently suggested (3), we might gag in the process. And the mechanism for setting priorities cannot be to identify with a group of special pleaders representing one's own vested interests, for the pie is equal exactly to the sum of its parts. If one piece is disproportionately large, other pieces will be disproportionately small.

(3) We must develop the capability for competing successfully for funds to support biomedical research and training. To do this we must establish a position of importance and visibility in the political system, without losing our basic identity. This, in my judgment, can be achieved best by enlisting the help of individuals with the type of expertise in the workings of government that we as a group have in the workings of biologic systems.

It is my hope that The American Society for Clinical Investigation will join together with its sister societies representing both clinical and basic aspects of biomedical research and teaching to find a common path to the achievement of our common goals.

This is a time for action. The time for reflection has passed.

\section{REFERENCES}

1. 1971. A policy for biomedical research. Report of an ad hoc committee of the Council of Academic Societies of the Association of American Medical Colleges. J. Med. Educ. 46: 691 .

2. Holmstrom, E. J., and L. M. Sharp. 1972. Studies evaluating $\mathrm{NIH}$ training grant and fellowship programs. V. Financing higher education-patterns of support for biomedical training. Report of Bureau of Social Science Research, Inc., June 1972.

3. Greenberg, D. 1970. The accountability of physicians and other scientists to society. Fed. Proc. 31: 1549. 